\title{
Managing resources in NHS dentistry: the views of decision-makers in primary care organisations
}

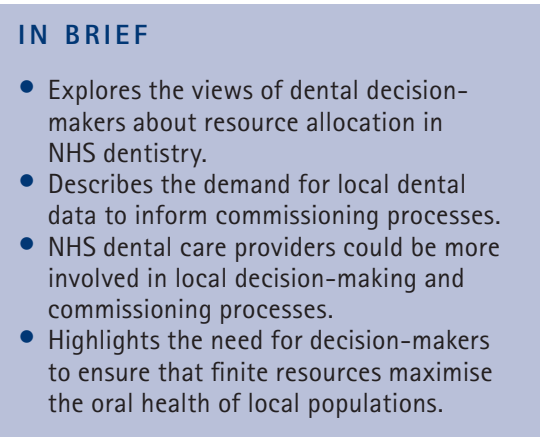

\author{
R. D. Holmes, ${ }^{1}$ C. Donaldson, ${ }^{2}$ C. Exley ${ }^{3}$ and J. G. Steele ${ }^{4}$
}

\begin{abstract}
Objective To investigate priority setting and decision-making in primary care organisations and to determine how resources are managed in order to meet the oral health needs of local populations. Method This is a qualitative study. The purposive sample comprised twelve dental public health consultants and six senior finance representatives from contrasting care systems across the United Kingdom. Participants completed a written information sheet followed by a recorded semi-structured telephone interview. Conversations were professionally transcribed verbatim and analysed independently by two investigators using the constant comparative method. Results The emergent themes focused upon: the role of participants in decision-making; professional relationships; managing change; information needs; and identifying and managing priorities. There was wide interpretation with respect to participants' roles and perceived information needs for decision-making and commissioning. A unifying factor was the importance placed by participants upon trust and the influence of individuals on the success of relationships forged between primary care organisations and general dental practitioners. Conclusion To facilitate decision-making in primary care organisations, commissioners and managers could engage further with practitioners and incorporate them into commissioning and resource allocation processes. Greater clarity is required regarding the role of dental public health consultants within primary care organisations and commissioning decisions.
\end{abstract}

\section{INTRODUCTION}

Demand for healthcare usually exceeds the resources available. The next question facing decision-makers should be how best to spend limited resources in order to maximise health benefit. Dental care is not alone; other health sectors similarly strive to balance need and patient demand against resource scarcity.

The responsibility for dental decision-making and resource allocation in

\footnotetext{
${ }^{1 *}$ Academic Specialist Registrar in Dental Public Health, School of Dental Sciences, Newcastle University, Framlington Place, Newcastle upon Tyne, NE2 4BW; ${ }^{2} \mathrm{Health}$ Foundation Chair in Health Economics/Director, ${ }^{3}$ Lecturer in Medical Sociology, Institute of Health and Society, Newcastle University, 21 Claremont Place, Newcastle upon Tyne, NE2 4AA; ${ }^{4}$ Clinical Professor/Consultant, School of Dental Sciences, Newcastle University, Framlington Place, Newcastle upon Tyne, NE2 4BW

*Correspondence to: Mr Richard Holmes Email:Richard.Holmes@newcastle.ac.uk
}

Online article number E12

Refereed Paper - accepted 27 May 2008

DOI: $10.1038 /$ sj.bdj.2008.755

${ }^{\circledR}$ British Dental Journal 2008; 205: E12
England and Wales has been devolved to primary care trusts (PCTs) and local health boards (LHBs), respectively. These organisations are now charged with commissioning appropriate dental services based upon local need. ${ }^{1,2}$ At the present time, dental care arrangements in Scotland and Northern Ireland remain under the historic general dental services (GDS) contract.

Primary dental care services provide over $90 \%$ of oral healthcare in the United Kingdom ${ }^{3}$ at an anticipated cost to PCTs in 2006-07 of £2.4 billion including patient charges. ${ }^{4}$ Research derived from the early personal dental services (PDS) pilots highlighted the value placed upon trust developed between clinicians and PCT staff. ${ }^{5}$ Several studies have made recommendations to strengthen the input of primary care stakeholders within health organisations, ${ }^{6,7}$ while others have noted potential concerns. ${ }^{8}$ The relatively small numbers of dental decision-makers within PCTs and the need for more dental expertise in commissioning decisions have been identified specifically. ${ }^{8}$

Whilst contrasting care arrangements exist for dentistry across the United Kingdom, the authors support an assertion made elsewhere ${ }^{9}$ that healthcare managers should have no more important activity than that of setting priorities and allocating resources. This aspect is of central importance to those managing the new general dental services (nGDS) contract at local levels, as well as areas that may do so at some point in the future. In England and Wales, primary care organisations (PCOs) have been charged with managing NHS dentistry with scarce resources. Local NHS organisations have never before held such an explicit and fundamental role in shaping dental services. An overview of the preparedness of PCOs to adapt to these changes is timely, as is an appreciation of the contrasting care arrangements which continue to operate in other areas 
of the United Kingdom. In the transition from contracting towards commissioning of primary care dentistry, this study aimed to investigate the perceived roles of PCO-based employees with respect to priority setting and resource allocation, together with a description of their strategies for ensuring the development of appropriate dental services tailored to the needs of local populations.

\section{MATERIALS AND METHODS}

The study comprised two stages: a postal information request and a recorded semi-structured telephone interview. A favourable opinion was received from the Newcastle and North Tyneside Local Research Ethics Committee [Ref 06/ Q0905/69]. A criterion-based purposive sample was drawn according to the variables shown in Table 1 . The selection criteria specifically incorporated contrasting dental care arrangements in various geographic locations, together with variables considered by the authors as most likely to influence the management of dental services at local levels. For the purpose of making the reader aware of the professional backgrounds of the authors, one is an academic dentist in a higher training programme who had no links with commissioning at the time of the study, the second author is a senior academic health economist, the third is an academic experienced in qualitative research, and the fourth is a senior academic working in a clinical dental speciality, again with no links to commissioning.

Consultants in dental public health were matched against the selection criteria using a list maintained by the British Association for the Study of Community Dentistry (BASCD). For each category, a single consultant was then identified. Those selected were contacted by letter and invited to participate. Finance representatives were identified in the same PCOs through 'snowballing' - using consultants' local knowledge to assist recruitment. The majority of individuals representing this professional group were directors or assistant directors of finance.

Participants received a postal information request with which to summarise their views on a range of topics including priority setting and resource allocation

\begin{tabular}{|c|c|}
\hline Variable & Description \\
\hline Geographical location (UK) & $\begin{array}{l}\text { North (Scotland) } \\
\text { South (Southern England) } \\
\text { East (Eastern England) } \\
\text { West (Northern Ireland) }\end{array}$ \\
\hline Population density & $\begin{array}{l}\text { Inner-city PCO } \\
\text { Rural PCO }\end{array}$ \\
\hline Fluoridated water & $\begin{array}{l}\text { Fluoridated PCO } \\
\text { Non-fluoridated PCO }\end{array}$ \\
\hline Deprivation & $\begin{array}{l}\text { Affluent PCO } \\
\text { Less affluent PCO }\end{array}$ \\
\hline Dental school & $\begin{array}{l}\text { PCO with local dental school } \\
\text { PCO with no local dental school }\end{array}$ \\
\hline
\end{tabular}

for dentistry. The intention was to prime participants ahead of a semi-structured telephone interview. On receipt of the completed information sheet, an investigator (RH) arranged and conducted all of the interviews following a topic guide. Interviews were recorded between 0ctober 2006 and February 2007 and were professionally transcribed verbatim. The data were analysed using the constant comparative method $^{10}$ - whereby data collection and analysis occurred concurrently. The resultant analysis was entered into a framework ${ }^{11}$ to assist data handling and organisation. One investigator (RH) trained in the analysis of qualitative data identified the main themes. Unmarked transcripts were also independently analysed by another member of the investigatory team (JS). Following independent analysis, both investigators met to identify and agree the thematic framework.

\section{RESULTS \& DISCUSSION}

Dental public health consultants were interviewed from ten English PCTs and two health boards operating under contrasting dental care arrangements in Scotland and Northern Ireland. The terms 'health board' and 'primary care trust' are collectively referred to as 'PCOs' unless discussion relates to a specific care system. Twelve settings allowed for a range of views and themes. One consultant declined to participate, citing pressure of work; however a replacement was found within the same sample category.

Five themes were identified from responses to the topic guide. Of the PCOs selected, six reported vacant senior finance positions at the time of recruitment and alternatives could not be identified. This finding reflected the impact of widespread re-organisation of many PCTs throughout the interview period. Despite these constraints, data saturation occurred within the themes generated by the finance representatives. Each theme is considered and discussed below.

\section{Theme 1: role of participants within PCOs}

Consultants' roles varied significantly and appeared to be controlled by the needs of their employing organisations. There was no clear consensus on the role of consultants with respect to commissioning and decision-making, and there appeared to be concern surrounding how their role was perceived at board level, particularly within English PCTs. One explanation for this belief related to the perceived cost of consultant positions in the current financial climate:

'I think consultants in dental public health are seen to be very expensive commodities... there's still a little confusion about the role of dental practice advisors and DPH consultants'. [Consultant ID1]

In contrast, finance directors clearly defined their position within PCOs and emphasised their chief role was to achieve financial balance. Directors of finance greatly valued the input and advice received from DPH consultants.

Several consultants introduced the concept of 'scale' by highlighting limitations imposed through working at the 
level of PCOs. On relatively large issues such as water fluoridation, the consensus was that their effectiveness as consultants may be better applied elsewhere:

'In a PCT you're actually at the bottom of the tree because you're only a little budget and you're performance managed. PCTs are not really the right remit... for water fluoridation which is why the SHAs are doing it... there's a limit to what you can do as a consultant in these environments'. [Consultant ID10]

Others recognised the constraints imposed through operating within relatively small PCOs and discussed how their role in future priority setting may be enhanced through serving multiple PCOs across larger geographic areas:

'I see this as a role for the SHA to make sure that in planning it's done on a sector-wide basis, rather than a PCO-wide basis... I would see my role... increasing within the SHA as an overview, rather than looking more at priority setting locally'. [Consultant ID9]

Consultants in particular reported feelings of instability and uncertainty, which is unsurprising considering the widespread structural re-organisations that occurred in many English PCTs at the time of the study. Uncertainty did not emerge as a concern in the health boards of Scotland and Northern Ireland, based upon the small number of interviews conducted.

In view of these findings, the role of DPH consultants would probably benefit from being defined more clearly by PCOs, both in general and commissioning terms. Greater clarity on consultants' roles may be an avenue that could be developed by strategic health authorities.

\section{Theme 2: professional relationships}

Maintaining good working relationships with colleagues was central to consultants' effectiveness with local decision-making. Not all the consultants interviewed had access to a dental practice advisor, but those who did valued them highly in terms of their local knowledge and ability to provide sound advice on a range of issues:

'We offer the services of a wiser practitioner to help with the business side and advice... they're worth their weight in gold'. [Consultant ID12]

Professional relationships between PCOs and practitioners were generally described as good. However, where conflict was experienced, consultants cited relations with local dental committees (LDCs) as an area of concern. The new general dental services (nGDS) contract appeared as the central theme and for practitioners, typically focused upon units of dental activity (UDAs). One consultant used the analogy of LDCs as a trade union with which to explain the potential for conflict:

'The relationship [with LDCs] will never be good, you have an understanding and mutual respect for each other... most of the time you're able to reach a compromise, but it's not always an amicable one and sometimes it can be painful.' [Consultant ID7]

Several consultants described LDCs as 'highly political' whilst some doubted their effectiveness in representing the views of the wider GDP community. However, the Department of Health has issued guidance to PCTs which specifically addresses this particular concern. ${ }^{12}$ Consultants recognised a need to involve clinicians in local decision-making, but cited barriers including the fact that individual personalities may play a significant role in determining the outcome of negotiations. Several GDPs were described as 'big hitters' with a high degree of political awareness and the ability to influence local LDCs. Similarly, consultants who experienced conflict were collectively bound by a perception that difficulties resulted from hidden agendas:

'There is a big voice on the LDC... they wouldn't want a PCO or consultant in dental public health at least at part of their meetings where they're discussing, you know... secret business'. [Consultant ID1]

With regard to the relationships developed between PCOs and local communities, both professional groups agreed that engagement was difficult unless the matter centred on key dental issues which directly affected the individuals involved:
'We have tried in the past to get lay implementation on many of our PCTwide strategic groups in terms of dentistry and it failed miserably to attract patient representatives. Patient groups are only interested when it's an issue.' [Consultant ID8]

While many organisations maintained close links with patient advice and liaison services (PALS), others reported that they did not actively consult service users for their opinions or involve them in decision-making because of issues including 'tokenism' and the perceived value of the selective responses received. However, engagement difficulties were not unique to health organisations and the general public. One consultant described a meeting with senior staff, highlighting the challenges faced by dentistry within some PCOs. The importance of individual personalities as a driving force was emphasised:

'When I saw the Director of Public Health they said 'well, you know, anything dentistry we just give to you and you deal with it' so it was a lack of engagement there. You have to get it on their main agenda... unless you're perceived to be reasonably passionate about the issues, you fold'. [Consultant ID1]

Outside the confines of PCOs, consultants described other professional relationships including working with members of parliament. Consultants viewed local MPs as 'facilitators' who frequently served to strengthen their own position within the PCO on issues of the day. MPs were judged effective at raising the profile of dentistry, particularly on access issues, and consultants thought the increase in media coverage helpful in bringing the problems faced by dentistry to the attention of their Executive Boards:

'If the MP is supporting the position you are putting forward, it is very strong... it makes a big difference... it makes life a lot easier having a politician working with you rather than against you'. [Consultant ID3]

Participants valued the relationships that had developed between themselves and local GDPs. However, while good 
working relationships with providers and performers were deemed a priority, there appeared to be limited opportunities, at the time of interview, for clinicians to widen their involvement in formal PCO-based commissioning and other decision-making processes.

\section{Theme 3: managing change}

The most significant changes were experienced by NHS participants in England and related to two issues: local PCO reorganisations and the nGDS contract. However, the effect of the latter issue affected consultants and finance representatives very differently. Several finance directors remarked upon the simplicity inherent in the new dental contract and described how their previous experience of the new general medical service contract meant that the period of time around its introduction had actually been relatively stress-free:

'It wasn't that stressful... there was much work to do and the fact that we actually delivered it, I find quite rewarding'. [Finance ID8]

However, this view was not shared by the majority of DPH consultants, who could be assigned to one of two categories based upon their level of involvement with managing nGDS negotiations with local GDPs. Consultants who became heavily immersed with negotiations typically reported that the volume and pressure of work had been unprecedented. Where this occurred, consultants stressed that they had not acted out of personal choice, but as a consequence of insufficient resources provided by their PCT:

'[This was] the most stressful and traumatic period I think in my professional career... antipathy towards the contract made the whole time around negotiations extremely fraught. There was very little commitment or support from the PCT in either financial or manpower terms'. [Consultant ID8]

\section{Theme 4: information needs}

One of the many skills afforded by DPH consultants is the provision of strategic advice based upon interpretation of relevant and high quality data. However, at its inception, the nGDS contract did not generate the detail and volume of activity recorded under the previous contract. The introduction of a new FP17 in April 2008 included an enhanced clinical data set in order to assist PCTs in their local commissioning responsibilities. ${ }^{13}$

Consultants discussed the limited value of national dental surveys in managing resources at a PCO level, however several referred to the benefit of being able to benchmark their respective populations against others:

'They're very useful for using as a comparison against local data because they're calibrated against a gold standard... they allow comparison between similar areas and benchmark where you are locally in terms of national targets for DMFT'. [Consultant ID2]

However, many participants highlighted a great need for more local dental data to inform decision-making and resource allocation. PCO-based dental surveys and oral health needs assessments were favoured data collection methods, however there were several barriers. Consultants cited poor response rates to local adult surveys and financial constraints within their PCOs as the major limitations:

'We've tried some local adult surveys but it's just a nightmare really... it's expensive... it's just not robust stuff'. [Consultant ID9]

\section{Theme 5: identifying and managing priorities}

Priority setting was frequently dominated by a single issue: patient access to dental care. Where this specific directive was broadcast by PCO executive boards or SHAs, it aided consultants in determining the main priorities:

'The SHA sets one priority - access to NHS delivery, this makes all resource allocation decisions relatively simple'. [Consultant ID3]

Another perceived influence upon local priority setting related to the financial position of PCTs in England. Many of the organisations recruited were reported to be focused upon 'balancing the books', especially during the period of local NHS re-structuring which occurred at the time of the study:
'During the next year 2007-2008, achieving financial balance will dominate priority setting and resource allocation in dentistry'. [Consultant ID5]

This approach led several participants to conclude that for the foreseeable future, decision-making would be driven by the state of PCT finances, despite reassurances to the contrary provided by the ring-fencing measures (now extended for a further two years until April 2011). ${ }^{14,15}$ As a consequence, several participants emphasised the need for dentistry to maintain its profile within PCTs in preparation for the wider roll out of dental commissioning:

'Once the three year salary guarantee ends then dentistry has to make its case. We need to look at what the health needs are and commission services to meet those needs - that may not necessarily sit with more of the same'. [Consultant ID7]

In many PCOs across the United Kingdom there appeared to be ongoing challenges in maintaining dentistry as a priority. It was suggested that this may be because dentistry may not adequately assist PCOs in achieving their measured national targets and objectives:

'If you look at what a PCO has got to do, preventing dental disease isn't ever a priority. They've got to meet waiting lists... what chance have you got? They say what's the point in having a Consultant in Dental Public Health, you're not going to help us meet our objectives... it is not a priority... if it's not "access" they don't really want to know about dentistry.' [Consultant ID10]

This perception was mirrored in the contrasting care arrangements in Scotland:

'We have very specific areas we must be seen to be delivering on... dentistry at the moment is not one of them... it's not on the radar'. [Finance ID6]

\section{Summary discussion}

The study represents a snapshot in time taken during a period of great change in NHS dentistry. While the findings of instability and uncertainty may be temporary, fundamental questions remain, such as how scarce resources are to be 
allocated at local levels together with who should be involved in commissioning processes. Participants in this study have highlighted the importance of developing professional relationships between the practitioners who deliver care and the PCOs who commission it. Engaging with GDPs and formally developing inclusive commissioning processes may facilitate greater understanding of the responsibilities and constraints experienced by both professional groups.

Further research is required to elicit how organisations manage their local dental services without input from resident DPH consultants; however, some of the consultants interviewed in this study worked across numerous health organisations and in this study, no significant concerns or issues emerged as a result of these networked arrangements. Despite the relatively restricted input to the discussion from senior finance personnel, the authors are of the opinion that their inclusion was justified. Data saturation was achieved relatively quickly with senior finance staff and this may reflect a lack of detailed knowledge about dentistry and/or that day-to-day management of this service remained firmly within the remit of DPH consultants in the PCOs studied.

At the time of interview, the authors noted the popularity of oral health needs assessments (OHNAs) in the PCOs studied. However, it was unclear to the authors how OHNAs would assist decision-makers to determine the size of future resource shifts, and fundamentally, how OHNAs on their own would attempt to maximise the oral health of local populations from scarce resources. The process of contracting appeared to dominate in English PCTs rather than true commissioning during the interview period, but there was general recognition by participants of the need to move away from 'historical' mechanisms towards processes which are equitable and transparent. ${ }^{16-18}$ Despite these opinions, explicit priority setting elsewhere in the NHS appears to present ongoing challenges for decision-makers. ${ }^{19}$

A cornerstone of effective commissioning ensures that resource provision reflects local need. Budgets based upon historic financial allocations do not necessarily address this principle, nor do health needs assessments always ensure that health (or capacity to benefit) is maximised.

\section{CONCLUSIONS \& RECOMMENDATIONS}

Many of the challenges highlighted could potentially be overcome through a small number of key actions:

1. PCOs could clarify the role of consultants in dental public health in their organisations and commissioning teams. Within any health organisation, somebody needs to make public health decisions on behalf of the local population, preferably on an informed basis. If these individuals are to be DPH consultants, PCOs could and should clarify their role and authority in local decision-making or make it clear on what basis local commissioning decisions are made

2. PCOs could ensure they engage and incorporate local GDPs in formal, structured commissioning processes

3. The position of dentistry within PCOs would benefit from greater clarity at national levels.

The move towards the wider commissioning of dental services in many areas of the United Kingdom marks an ideal opportunity to begin the planning of formal, inclusive commissioning processes.

The authors would like to express their gratitude to the consultants in dental public health and PCO-based finance representatives who participated in the study. We would also like to thank Angela Bate for her assistance with design of the information requests.
1. Department of Health. NHS dental reforms: one year on. London: Department of Health, 2007.

2. Primary Care Contracting. Oral health needs assessment toolkit for primary care trusts. London: Primary Care Contracting, 2006.

3. Palmer N, Batchelor P. Informing research in primary dental care: setting priorities. Primary Dent Care 2006; 13: 85-90.

4. Department of Health. Implementing local commissioning for dentistry webpage. http://www. dh.gov.uk/en/Aboutus/Chiefprofessionalofficers/Chiefdentalofficer/DH_4138919 (accessed 14 August 2008).

5. McLeod H S T, Morris A J, Hill K B. Evaluation of personal dental services (PDS) first wave pilots: the alternative to general dental services (GDS) offered by the capitation-based pilots. Br Dent J 2003; 195: 644-650.

6. Jessop N M, Kay E J, Mellor A C, Whittle J G, Jenner $A$. The ability to successfully include primary dental care practitioners in commissioning groups. BrDent J 2000; 189: 675-677.

7. Jessop N M, Kay E J, Mellor A C, Whittle J G, Jenner A. Past and present attempts to control health service expenditure and its effects on National Health dentistry. Br Dent J 2000; 189: 617-619.

8. Goodwin N, Morris A J, Hill K B, McLeod H S, Burke FJ T, Hall A C. National evaluation of personal dental services (PDS) pilots: main findings and policy implications. Br Dent J 2003; 195: 640-643.

9. Mooney G, Wiseman V. Listening to the bureaucrats to establish principles for priority setting. Sydney, Australia: University of Sydney, 1999.

10. Glaser B G. The constant comparative method of qualitative analysis. Social Problems 1965; 12: 436-445.

11. Ritchie J, Spencer L, O'Connor W. Carrying out qualitative analysis. In Ritchie J, Lewis J (eds) Qualitative research practice: a guide for social science students and researchers. pp 219-262. London: Sage Publications, 2003.

12. Department of Health. Implementing local commissioning for primary care dentistry. Factsheet 16 - local dental committees. London: Department of Health, 2006, Gateway Reference 6985.

13. Department of Health. Chief Dental Officer's update, March 2008. pp 4. London: Department of Health, 2008.

14. Department of Health. Implementing local commissioning for primary care dentistry. Factsheet 4 - PCT dentistry budgets 2006/07 \&t patient charge income. London: Department of Health, 2005 Gateway Reference 5917.

15. Department of Health. Dentistry graduates to complete training in areas of patient need. News release. London: Department of Health, 2008. http://www.dh.gov.uk/en/News/Recentstories/ DH_083330 (accessed 14 August 2008).

16. Doyal L. Rationing within the NHS should be explicit: the case for. BMJ 1997; 314: 1114-1118.

17. Daniels N, Sabin J. The ethics of accountability in managed health care reform. Health Affairs 1998; 17: 50-63.

18. Gibson J L, Martin D K, Singer P A. Priority setting in hospitals: fairness, inclusiveness, and the problem of institutional power differences. Soc Sci Med 2005; 61: 2355-2362.

19. Bate A, Donaldson C, Murtagh M. Managing to manage healthcare resources in the English NHS? What can health economics teach? What can health economics learn? Health Policy 2007; 84: 249-261. 